\title{
VALIDATION OF SIMULTANEOUS ASSAY OF CLOZAPINE AND ITS MAIN METABOLITES IN BLOOD SERUM USING HPLC-MS/MS METHOD
}

Article history:

Submitted 20 June 2019

Accepted 31 July 2019
Olga L. Romanova ${ }^{1,2^{*}}$, Dmitriy V. Sundukov',
Arkadiy M. Golubev ${ }^{1,2}$, Mikhail L. Blagonravov

${ }^{1}$ RUDN University, Department of Forensic Medicine, Moscow, Russia ${ }^{2}$ Federal Research and Clinical Center of Intensive Care Medicine and Rehabilitology, Moscow, Russia

${ }^{3}$ RUDN University, V.A. Frolov Department of General Pathology and Pathological Physiology, Moscow, Russia

*Corresponding Author: olgpharm@yandex.ru

\section{INTRODUCTION}

Clozapine is an atypical antipsychotic drug. It is frequently used in clinical practice. The number of criminal clozapine poisonings remains high. Clozapine is metabolized in the liver. Its main metabolites are norclozapine and clozapine-N-oxide [1]. According to the literature these metabolites have their own toxic effect [2]. However there is no validated method of simultaneous assay of the substances.

The aim of the study is to carry out the validation of simultaneous assay of clozapine and its main metabolites - norclozapine and clozapine-N-oxide - in blood serum using HPLCMS/MS method. We represented calibration curves for clozapine and its main metabolites. We assessed the following parameters: selectivity, precision, accuracy, matrix effect, lower limit of quantification [3].

\section{MATERIALS AND METHODS}

The validation was carried out using chromatograph Agilent Technologies 430 Triple Quad LC/MS (Germany). We used PC programme Agilent Mass Hunter Workstation for series tripple Quadrapole vers. B06.00 build 6.0.6.25.4sp4 to represent chromatograms and Agilent Mass Hunter Quantitive Analysis vers. B 07.00 build 7.0.457.0 to proceed them.

\section{RESULTS}

Calibration curve. We used six levels of concentration for clozapine. The range of concentrations was from 0,125 to $5 \mu / \mathrm{ml}$. Relative standard deviation (RSD) for used clozapine levels did not exceed $15 \%$, accuracy was between $88,15 \%$ and $109,51 \%$. We used seven levels of concentration for norclozapine. The range of concentration was from $0,0075 \mathrm{AO} 7,5 \mu / \mathrm{ml}$. Relative standard deviation (RSD) for used norclozapine levels did not exceed 15\%, accuracy was between $80,13 \%$ (concentration level 1 ) and $106,51 \%$. We used five levels of concentration for clozapine- $\mathrm{N}$-oxide. The range of concentration was $0,03-3,00 \mu / \mathrm{ml}$. Relative standard deviation (RSD) for used levels of clozapine$\mathrm{N}$-oxide did not exceed $15 \%$, accuracy was between $81,20 \%$ and $98,30 \%$.

Precision and accuracy. Precision and accuracy for QC samples should not exceed 15\% except the one for the LLOQ which should not exceed $20 \%$. We assessed the precision and accuracy 3 times in $4 \mathrm{QC}$ samples QC_1, QC_2, QC _3, QC_4 at the expected range of concentrations. All the figures we obtained met the criteria.

Lower limit of quantification. The lower limit of quantification (LLOQ) is the lowest concentration of analyte in a sample which can be quantified reliably, with an acceptable accuracy and precision. The LLOQ is considered being the lowest calibration standard. The lower limit of quantification we obtained for clozapine was $0,05 \mu / \mathrm{ml}$. The signal/noice ratio $(\mathrm{S} / \mathrm{N})$ was 0,12 . The lower limit of quantification we obtained for norclozapine was $0,0025 \mu / \mathrm{ml} ; \mathrm{S} / \mathrm{N}$ was 0,14 . The lower limit of quantification we obtained for clozapine- $\mathrm{N}$-oxide was $0,001 \mu / \mathrm{ml} ; \mathrm{S} / \mathrm{N}$ was 0,10 .

Recovery. The recovery rate for clozapine was measured at concentrations of $5 \mu / \mathrm{ml}$ and $0,25 \mu / \mathrm{ml}$, the recovery rate for norclozapine was measured at concentrations of $0,5 \mu / \mathrm{ml}$ and $0,1 \mu / \mathrm{ml}$, clozapine-Noxide $-1 \mu / \mathrm{ml}$ and $0,03 \mu / \mathrm{ml}$. The recovery rate for each analyte and inner standard (IS ) - amitriptyline - was estimated separately. The recovery rate for clozapine was $86,6 \%$, the recovery rate for IS exceeded $99 \%, \mathrm{CV}<15 \%$. The recovery rate for norclozapine was $63 \%$ the recovery rate for IS exceeded $93 \%, \mathrm{CV}<15 \%$. The recovery rate for clozapine- $\mathrm{N}$-oxide was $84 \%$ the recovery rate for IS exceeded $97 \%, \mathrm{CV}<15 \%$.

\section{CONCLUSION}

The validated method can be used for simultaneous assay of clozapine, norclozapine and clozapine- $\mathrm{N}$ oxide in blood serum. 